\title{
The Countermeasures of Development Modern Logistic Industry in Liaoning Province
}

\author{
Tao Zhao \\ Management science and engineering, Wu Han University of Technology \\ Xiong Chu Street, Wu Han 430070, China \\ E-mail: chengw523@163.com \\ Junjing Li \\ Management science and engineering, Shenyang University \\ 21 Wang Hua South Street, Shenyang 110044, China \\ E-mail: lijunjing123@126.com \\ Wei Cheng \\ Management science and engineering, Shenyang University \\ 21 Wang Hua South Street, Shenyang 110044, China \\ E-mail: lijunjing0811@126.com
}

\begin{abstract}
Modern logistics has become the main driving force of economic growth in Liaoning major industries; accelerating the development of modern logistics industry in Liaoning is realized the main economic growth approach. In this paper, aim at the development of the logistics situation, the objective analysis of the modern logistics industry problems in Liaoning, while at the same time how to develop modern logistics industry in Liaoning has been brought forward a countermeasure.
\end{abstract}

Keywords: Modern logistics, Current situation, Countermeasure

\section{Introduction}

Modern logistics industry is an emerging complex industrial, including activity such as transportation, storage, packing, handling, distribution, distribution processing, information processing and other activities. Modern logistics has become the main driving force of economic growth in major industries of Liaoning, with the fact that Liaoning opening to the outside world in all directions expands further, accelerates the development the modern logistics job have important practical or immediate significance and long-term strategy significance to realizing economy great-leap-forward development.

\section{Liaoning development statuses}

\subsection{Transport logistics}

Liaoning is a big transport province, has been basically completed the seaports, airports, railways, highways, pipelines and five body's stereo metric formulas, the modernized transport network and the quite developed collection moves out the system. It basically has been achieved high-speed highway, railway electrification, aeronautical technology, deep water port and containerization. However, the main channels of Liaoning lack of coordination between different modes of transport, short distance between the primary hub port and cargo kind of cross-evident, coordination is not in place, there is poor competition.

\subsection{Trade \& Logistics}

Liaoning Province's trade logistics have become the leading model for stimulating national economic growth pillar industries. Liaoning Province in 2007 retail sales amounted to 403.01 billion Yuan, up 118.1 percent over 2000 (Li Hui, 2009, p.57). Wholesale and retail trade the entire province to achieve a value of 336.17 billion Yuan, compared with an increase of 49.14 billions Yuan in 2006. Ten thousand meters the above large-scale emporium, major supermarket chains reached 50 as many as 3,300 various types of commodity trading markets. 
The big companies and big groups very rapid development and the rapid development of new circulation types. Statistics show that in 2006 the city added 1,364 stores, all quantity reaches more than 8,500, accounting for total retail sales of social consumer goods up $22.3 \%$ over 2005 by 1.6 percentage points (Zheng Deyan, 2001, p.20). But the overall look, Liaoning trade logistics is still in the preliminary stages of construction, uneven development, there are many issues need to be solved, for example: logistics center is not a scale; logistics personnel shortage; socialization distribution center operation and system insufficiency circulating to synthesize an article etc.

\subsection{Telecommunications, logistics information industry}

Liaoning province dispatch, information infrastructural facilities are fine. The whole province owns long-distance optical cable general the length 11,000 is many kilometer, dry, branch optical cable with a total length more than $46,000 \mathrm{~km}$, communications lines and transport networks and regional networks achieved $100 \%$ and digital cable, public data communication network has been established, initially formed the "information superhighway" of the basic framework. End to May 2008, Liaoning province telephone penetration rates exceed 95 hundred people, 5100 marks burn than having been advanced in 2007. Internet broadband subscribers reached 3,607,700, up 37\% during the year added 330,000. Mobile packet data users reached 3.93 million. In 2008, Liaoning's information industry realized added value of 68.4 billion Yuan, up 22.4\%; realized profits of 11.3 billion Yuan, up 14.1\%.Software (Cheng Wei, 2009), the develop rapidly communicating by letter waiting for new industry, the income from sales of products already accounts for that whole province IT industry sells a general income 38\%, whole province IT industry inner structure optimizes further. 600 software enterprises in the province have been as many as initially formed to Dalian, Shenyang-based to a large display, key enterprises in China and China recording a development pattern for the pillars.

\subsection{Bonded logistics}

Shenyang Bonded Logistics Center (B type) will rely on Western Shenyang Industrial Corridor advantage of strong industry clusters, under the supervision of the customs, focusing on bonded warehousing, simple processing and value-added services, international logistics and distribution, import and export trade, international transit and re- logistics information processing business, providing customers with the versatility of radiation at home and abroad, and comprehensive integration of bonded service. Bonded logistics center in Shenyang backed Free Trade Zone is being integrated offshore applications; the establishment of comprehensive free trade zone on the driving economic growth in Liaoning plays an essential role.

Although the information in the application of modern logistics has made remarkable achievements in information technology to transform traditional logistics industry achieved initial success, but there are still many problems. Such as: irrational industrial structure, industry small scale, low key enterprises, supporting weak; all its resources and less to the flow of information industry inclined; lack of modern logistics, management system backward.

\section{Liaoning logistics problems}

\subsection{Logistics enterprises are small, single function}

At present, most logistics enterprises in Liaoning Province is still in "small and scattered" growth period, compared with international multinational corporations have a large gap, international competitiveness is still weak. To provide logistics services or general transportation and warehousing services to individual or section, for logistics information, logistics and other value-added services, design is not good enough, regional, transnational and even fewer large-scale logistics group.

\section{2 "Fragmentation, fragmentation" of the logistics management system}

Liaoning has been the number of government departments "division of labor management" to manage the province's logistics activities, these departments are an integral part of the provincial government, have jurisdiction over the province of logistics. Such as: Ministry of Railways Railway logistics management for the province; Ministry responsible for roads, logistics, shipping logistics management; Civil Aviation Administration for aviation logistics management. This fragmentation of co-ordination of logistics management system, not only the logistics planning and logistics Liaoning industrial policy is difficult to unity, but also logistics tools, equipment and technical standards is difficult to unity, which seriously affected the province's logistics efficiency. In addition, most of Liaoning Province, self-logistics business sector is still very strong will, are not used, do not want, do not trust the company's logistics market. 


\subsection{The lack of logistics professionals}

Modern logistics industry, logistics, information flow, capital flow operational needs of high-quality unified planning and management of logistics personnel. Because education in logistics at my country is still very backward, set the little Logistics Management College, and most recent years of the new, post-graduate education and vocational education is only just starting, logistics, personnel training and quality scale far from meeting the demand for logistics professionals, making the logistics industry practitioners in Liaoning generally low quality, logistics personnel, especially proficient in modern logistics, technology, management, operation, service and development of complex talent shortage.

\subsection{Logistics technology behind}

Mainly in logistics equipment behind the low level of logistics operations, processes, inadequate management, logistics and systematic feature is not fully functional and so on. If the system functions in logistics, warehousing and transportation functions lack of functional coordination, long-distance transportation and short distance delivery lack of effective convergence, poor integration of various modes of transport, to provide comprehensive agent, "one vote in the end" and "door to door" enterprise that logistics serves is less.

\section{Liaoning development strategies of modern logistics}

\subsection{To establish mechanisms for coordination and management}

Partitioning easy to appear manages, political affairs puts up many doors problem specifically for logistics system, be necessary whose duty, farm-out reinforcing the coordination service ability between government departments, uniting cognition, every department, build a high efficiency government coordination managing mechanism. In respect of all functions based on the comprehensive economic administrative departments led by provincial, transport (including railway and civil aviation), trade, industry and commerce, taxation, customs and other relevant departments to participate, form a high-level coordinating body, unified leadership, coordination of all Province logistics development, so that the logistics chain in Liaoning Province in all aspects connected with each other to form an organic system.

\subsection{The establishment of regional surveillance system, logistics, information sharing}

Logistics information technology is a core project in Northeast. Construction according to the guidelines of national and provincial major cities of information "Eleventh Five-Year Plan", relying on and strengthening the basis of broadband multimedia information transmission network to establish and improve global supply chain and close to the customer service local network, local network and transnational networks as the main goal, to integrate the various information communication resources, in North Eastern overall function of the modern logistics industry, efficiency and effectiveness for the purpose, acceleration building-up concentrates system, realization information share and distribution, the entity monitor with supposing the common unified information being tied in wedlock each other to serve platform, basis data base network system and regional logistics synthetically, boost modern logistics of northeast China putting to use in production actively, cluster-rization, intension and internationalization develop a course.

\subsection{Vigorously train logistics personnel}

As information technology and management level increased, competition in the modern logistics industry price competition from low-end high-end logistics and information flow turning capacity of competition. Therefore, the market needs a large number of modern logistics personnel: from the demand area, the main focus in the enterprise, planning and consulting, research and teaching institutions such as the three major areas; from the hierarchy of needs analysis, mainly logistics operators, logistics managers and the actual senior logistics management personnel at three levels. However, as has long been "heavy manufacturing, light distribution," the shackles of traditional thinking, not only lower the level of logistics and logistics education lagged behind the development of the logistics industry and national economic development, causing a serious shortage of logistics personnel. Therefore, the implementation of the logistics personnel training projects, creating a large number of good use of modern means of information, proficient in logistics business, understand the law of logistics expertise, to address the shortage of logistics personnel, reduce the development gap with the developed countries, the logistics industry is significant.

\subsection{Shenyang Bonded Logistics-based development of a comprehensive Free Trade Zone}

With the support of bonded logistics of Shenyang centre (B type), the proposed comprehensive Free Trade Zone should be established in Shenyang, Northeast China and the formation of an integrated strategy for the integrated development of Free Trade Zone, Shenyang, coastal waters that is comprehensive Free Trade Zone, Suifenhe 
comprehensive Free Trade Zone, a long northeast comprehensive Free Trade Zone, Dalian Dayaowan integrated development of the bonded port area will lead to an international market, highly open free trade zone. Integrated comprehensive coastal waters after the transition, the main function is bonded processing free trade zone, bonded logistics, bonded trade and trade related services to attract multinational companies, import and export enterprises in the cost, efficiency and degree of freedom under consideration and compared to its cross-border value chain more The link to have in the special region, driven in Shenyang and the surrounding areas of advanced manufacturing and modern service industries.

\subsection{Axis of the city - Shenyang, Dalian, Jinzhou - Huludao Development party logistics, the logistics public information platform built in Liaoning}

The Liaoning axle centre city Shenyang, Dalian, Jin Zhou- Hu Lu Dao form via the Internet can be integrated logistics company (including Third Party Logistics Company) resources to make Liaoning province logistics estate rise having quality really. Many current logistics network companies to integrate certain social resources and social impact of a certain few, the current focus on fostering the development of Fourth. Fourth Party Logistics in solution based on the integration of social resources to address the full sharing of logistics information, community resources and make full use of logistics problems. Also function as a Government. In promoting the development of modern logistics industry can do all the people the only point. Therefore, the development of fourth party logistics has become a must.

\subsection{Radiation urbans develop functional third-party Logistics Company}

Modern highly integrated logistics industry determines the information and standardization is an important foundation for industrial development. As china's logistics industry into the development of pragmatic, government, enterprises, trade organizations and scientific institutions give much attention to the logistics information, standardization from a policy, funding, research and development etc, so that the logistics public information platform, enterprise logistics information technology, information technology and logistics standardization makes considerable progress in building. The central nervous of the third logistics is logistics information system, it plays support and protection role in the operation of logistics (He Dengca, 2006, p.15). On one hand, it is to master the dynamic logistics supply chain through real-time, order from a cargo shipment, to third-party Logistics Company controlled by the coordination of a series of links, then the goods to the consignee in the hands, makes the logistics supply chain transparency as far as possible. Help supply chain companies to predict future market conditions and trends, to provide the basis for marketing strategy model, accelerate the pace of business cash flow, additional profits for the enterprise. On the other hand, for third-party logistics itself, the use of logistics information system, can effectively regulate the business operation of logistics business processes, reduce operational errors. Though the analysis and use of standardized data in logistics system, to improve the management of logistics operations, and provide quality services to customers, enhance the competitiveness of logistics enterprises.

4.7 Construction "axis of radiation-type" of supporting facilities about regional logistics integrated system of Liaoning

In the "axis of radiation-type" logistical integration mode, there are three major logistics hub of Shenyang, Dalian, Jinzhou and Hu Ludao,as is the axis of axis of a radiation of system. However, there is the function of these three axes is not enough to full play. Part of the axis of the logistics infrastructure has not keep up with the development of economic. Therefore, we must strengthen the axis of urban development, and improve its integrated business processing capabilities. The radiation city should strengthen the construction of logistics channel, and strength the route network functions.

\section{Summaries}

The importance of logistics has become increasingly apparent, logistics management's role in enterprise management is also quite a lot, to speed up the development of logistics industry, Liaoning must understand the development of logistics current situation and existing problems, and take the necessary measures for improving the problems. National local governments at all levels and all enterprises hand in hand to promote the development of modern logistics industry in Liaoning province.

\section{References}

Cheng Wei, Zhao Tao and Li Junjing. (2009). International Logistics Center of Northeast Asia's Business and the Mode of Operation Design. World Academic Union.

HE Dengca. China Logistics Department Report. (2006). China Logistics Publishing House, 15-18 
Li Hui and Wu Huifang. (2009). Modern logistics development and countermeasures in china. Journal of hebei tourism vocational college, 57-58

Zheng Deyan. (2001). The analysis of function locationin Free Trade Zone. Economist, 20-21 